\title{
Nômade de olhar atento e traço certo: Mário de Miranda, a arte da caricatura e os desencontros entre o mundo indiano e o olhar ocidental
}

\author{
Joana Passos \\ Centro de Estudos Humanisticos da Universidade do Minho
}

\begin{abstract}
RESUMO: A ANÁLISE DE TRÊS CARICATURAS FEITAS PELO AUTOR GOÊS MÁRIO DE MIRANDA SERÁ ENQUADRADA POR UMA REVISÃO DA HISTÓRIA DA CARICATURA, ACOMPANHADA DE UMA REFLEXÃO TEÓRICA SOBRE AS CARACTERÍSTICAS DO GÊNERO. PARA DISCUTIR COMO AS CARICATURAS SELECIONADAS COMPARAM IRONICAMENTE OCIDENTE E ORIENTE, SUBLINHANDO FORMAS DE CONTAMINAÇÃO E HIBRIDISMO CULTURAL, RECORREMOS À TEORIA PÓS-COLONIAL COMO MODELO CRÍTICO.
\end{abstract}

ABSTRACT: THE DISCUSSION OF THREE CARICATURES BY THE GOAN ARTIST MÁRIO DE MIRANDA WILL BE FRAMED BY A BRIEF HISTORY OF THE GENRE AND A THEORETICAL DISCUSSION OF ITS STRUCTURAL FEATURES. AS THE SELECTED CARICATURES FEATURE AN IRONIC COMPARISON BETWEEN EAST AND WEST AND HIGHLIGHT FORMS OF CONTAMINATION AND CULTURAL HYBRIDITY, MY ARGUMENT WILL USE POSTCOLONIAL THEORY AS ITS CRITICAL MODEL.

PALAVRAS-CHAVES: MARIO DE MIRANDA, CARICATURA, HIBRIDISMO CULTURAL, CRÍTICA PÓS-COLONIAL KEYWORDS: MARIO DE MIRANDA, CARICATURE, CULTURAL HYBRIDISM, POSTCOLONIAL CRITIQUE 
ário de Miranda, autor indiano do Estado de Goa, cultivou a arte do desenho e da caricatura ao longo de uma longa carreira com reconhecimento internacional. A arte que escolheu cultivar, a caricatura, não é comumente considerada cultura de elite, por estar associada ao mundo da imprensa, ao humor, e ao consumo popular. No entanto, o olhar crítico de Mário de Miranda enquanto comentador da vida pública, bem como a qualidade estética do seu traço, valeram-lhe um estatuto de autor de referência dentro desse millieu específico. Mário de Miranda desenvolveu a sua carreira sobretudo no The Times of India, mas viria a expor em várias cidades europeias e foi artista residente de inúmeras companhias e embaixadas.

O estudo da obra caricatural de Mário de Miranda servirá de mote para uma revisão da história da caricatura, acompanhada de uma reflexão teórica sobre algumas das suas características fundamentais enquanto signo composto por elementos visuais e verbais. Como caso de estudo, este artigo oferece a análise de um conjunto de caricaturas de Mário de Miranda, na qual se justapõe o Ocidente e o Oriente, desconstruindo preconceitos eurocêntricos e as concomitantes expectativas orientalistas, que persistem como traços da mentalidade popular no Ocidente.

Uma caricatura é um desenho tradicionalmente acompanhado por um pequeno texto ou um curto diálogo que tem a função de orientar o público/o leitor a interpretação da imagem. A característica distintiva desse conjunto composto por texto e imagem é o impacto pretendido pela caricatura. Ao contrário, por exemplo, de textos pedagógicos ou de sinais informativos, que também recorrem a uma imagem apoiada por um texto, o fim último da caricatura é o humor, ou seja, provocar o riso. Isso não quer dizer que, enquanto comentário social e/ou político, a caricatura não tenha uma função informativa válida. Simplesmente, ao apelar ao humor, a caricatura entra num jogo cúmplice, indireto e mediado, com o seu público. Nas palavras de Osvaldo de Sousa, autor de uma válida história da caricatura em Portugal, o humor será mesmo o aglutinador das variantes desse subgênero, tal como cultivado em diferentes sociedades e em diferentes épocas:

Pode cada historiador ter a sua concepção da importância do humor, da caricatura, do grotesco na história de cada sociedade, porém todos são unânimes em que o sentimento do ridículo é de todos os tempos. 
O mesmo não se poderá dizer dos motivos risíveis, pois cada sociedade, cada época, ri do que mais admira, ou teme, matizando as formas do riso. O humor é, na sua essência, um jogo de inteligência, de cultura, e só se pode concretizar quando o receptor compreende a mensagem humorística, quando está dentro da simbologia, do conhecimento desenvolvido em sátira, ironia ou paródia. (SOUSA, 1991, p. 1)

Se a essência da caricatura é o humor associado à expressão de uma visão crítica social e/ou política, estamos então perante uma forma de arte comprometida, que pode ser mais superficial ou de maior profundidade filosófica, consoante o seu autor. Admitindo a segunda possibilidade, a caricatura tornase um objecto de estudo mais complexo e sociologicamente mais significativo, sendo tanto mais representativa de uma dada sociedade e das questões com que ela se debate consoante a sua ampla circulação e popularidade (a popularidade de uma caricatura advém da sua pertinência e do fato de o público reconhecer a sua temática). Normalmente, concebemos que o meio de difusão da caricatura é a imprensa escrita, pressuposto que não está incorreto se tivermos em mente uma noção moderna de caricatura, panfletária, provocadora, popular e de ampla circulação, mas a caricatura tem uma história mais antiga, anterior à circulação generalizada da própria imprensa.

A caricatura já existe desde o século XVII, mas nessa altura não era conhecida fora de um circuito fechado, boêmio, artístico, onde todos se conheciam, e conheciam também a figura da nobreza ou do clero que pela caricatura era ridicularizada. Era uma brincadeira privada, irreverente, que tomava como alvo determinadas instituições ou formas de autoridade. No século XVIII, a caricatura manteve essa lógica estrutural, mas ganhou outra divulgação ao ser impressa sob a forma de panfletos políticos que promoviam determinadas ideias reformistas ou revolucionárias. Os panfletos eram distribuídos na rua, ou vendidos por um preço módico, e é nesse momento, de ampla circulação e de democrático acesso urbano, que a caricatura ganha um público popular, vernáculo, para além dos meios artísticos boêmios e irreverentes. Recordemos que a litografia, o meio técnico que permite a reprodução de desenhos, foi inventada em 1798.

A teorização da caricatura começou na França, durante o século XVIII, associada à sua circulação panfletária. Já existe uma entrada para o termo "ca- 
ricatura" em 1751, na Encyclopédie ou Dictionnaire Raisonné des Sciences. Contudo, o primeiro ensaio no qual se discute seriamente a natureza da caricatura é de 1885, e foi escrito pelo pensador e poeta francês Charles Baudelaire (18211867), com o título "De l'essence du rire”, a que se seguiu "Quelques caricaturistes français" e "Quelques caricaturistes étrangers". Nesses ensaios, Baudelaire define a caricatura como um género vernacular, popular e baixo, ao nível do "calão" (linguagem imprópria e rude). Acontece que, apesar de ser um género vernacular, Baudelaire lhe reconhece elevação e valor, como expressão de uma época e de uma sociedade, e detentora de uma estética própria, na qual se explorava o feio e o disforme com o intuito de provocar o riso:

Sem dúvida, uma história geral da caricatura que a abordasse nas relações com todos os acontecimentos que agitaram a humanidade, os políticos e os religiosos (sérios ou fúteis) e os relativos ao espírito nacional ou à moda, seria uma obra gloriosa e importante. [...]

$\mathrm{Na}$ caricatura, muito mais do que em outros campos da arte, existem dois tipos de obras preciosas e recomendáveis, diferentes e quase contraditórios [...] As folhas de papel efêmeras do jornalismo, [...] (e aquelas) que contêm um elemento misterioso, perene, eterno, que exigem cuidado dos artistas. [...] São obras destinadas a representar ao homem a sua própria falibilidade moral e física! E, coisa não menos misteriosa, esse espectáculo lamentável provoca nele uma hilaridade imortal e incorrigível. (BAUDELAIRE, s.d., vol. II, p. 525-526) ${ }^{1}$

Charles Baudelaire não negava o valor moralizante nem a função de crônica de costumes que se reconhecia à caricatura e, por isso mesmo, assumirá a apropriação de alguns dos elementos desse subgênero do desenho para a construção de poemas que denomina de argot poétique, ou seja, "gíria poética”, em que explora o repulsivo, o feio ou o disforme com uma intenção

1. Sans doute une histoire générale de la caricature dans ses rapports avec tous les faits politiques et religieux, graves ou frivoles, relatifs à l'esprit national ou à la mode, qui ont agité l'humanité, est une oeuvre glorieuse et importante. [...] Dans la caricature, bien plus que dans les autres branches de l'art, il existe deux sortes d'oeuvres précieuses et recommandables à des titres différents et presque contraires. [...] Les feuilles volantes du jornalisme [...] (et celles) que contienne un élement mysterieux, durable, éternel, qui les recommande à l'attention des artistes. [...] Les oeuvres destinées à représenter à l'homme sa propre laideur morale et physique! Et, chose non moins mystérieuse, ce spectacle lamentable excite en lui une hilarité immortelle et incorrigible. (Baudelaire, s.d., v.II: 525-526, minha tradução.) 
irônica e reflexiva. Será importante reter essa noção do "culto do feio" para compreendermos a própria evolução da caricatura. Os desenhos caricaturais afirmaram a sua identidade própria precisamente por rejeitarem padrões do belo ou de equilíbrio harmonioso nos seus retratos de figuras conhecidas. Ou seja, a caricatura vincava os traços menos harmoniosos ou menos clássicos no rosto de uma dada personagem pública, explorando as características mais idiossincráticas e grotescas.

No século XIX, com a implantação da imprensa, seja sob a forma de jornais ou sob a forma de almanaques ou outras revistas periódicas, a caricatura consolida a sua presença junto ao público, refinando-se graficamente e tornando-se um temível meio de crítica social e política, quer pela popularidade, quer pela difusão, que significavam para o visado uma grande exposição e humilhação pública. É de realçar que mesmo um público analfabeto, nas ruas de Paris ou Lisboa, conseguia compreender e reconhecer a lógica da caricatura, o que a tornava um eficaz meio de comunicação, muito mais poderoso do que um texto escrito.

No século XX, por influência da evolução estética do desenho moderno, e também pelo crescente estatuto da caricatura como forma da arte gráfica, ocorre uma renovação dos padrões estéticos e formais da caricatura, que levam a um maior decoro e contenção na forma de tratar os temas ridicularizados, mas essa elegância no tratamento do tema não significou qualquer perda de impacto, de popularidade, ou da capacidade de "atacar" uma dada personagem ou situação. Por seu turno, em termos formais e técnicos, a tradição do desenho moderno, ligada à pintura e à arquitetura, levou à simplificação da composição. Os elementos da imagem tornaram-se mais simples, geométricos e estilizadao, afastando-se dos das imagens do século XVIII e XIX, que eram mais cheias de detalhes, mais pesadas, com algum ruído visual. Uma outra diferença marcante entre a caricatura do século XIX e a caricatura moderna é que, embora a caricatura sempre deforme e exagere a realidade representada, as caricaturas anteriores às do século XX são mais realistas e, por conseguinte, menos estilizadas. A fim de ilustrar o que aqui se pretende dizer, apresentamos dois exemplos concretos: 


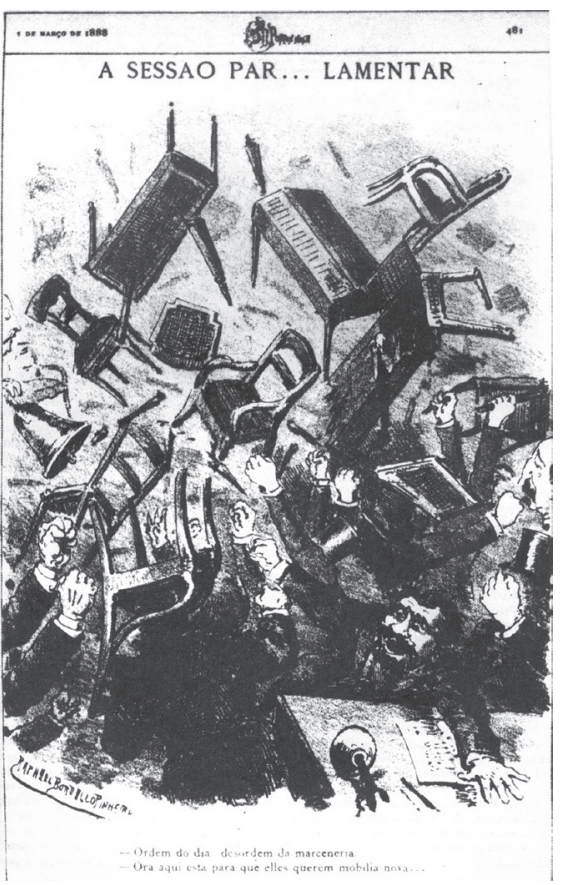

Figura 1 “Sessão par...lamentar" (1888) por Rafael Bordallo Pinheiro, apud Osvaldo de Sousa, A caricatura política em Portugal, 1991: 34.

Tomemos como primeiro exemplo uma caricatura de Rafael Bordallo Pinheiro (1846-1905), figura emblemática na consolidação e reconhecimento desse subgênero artístico em Portugal. Na sua caricatura "A Sessão par...lamentar" (apud SOUSA, 1991, p. 34, original de 1888) as cadeiras voam pelos ares, juntamente com pedaços de madeira partida, e diversos punhos fechados, ameaçadores, cruzam-se numa confusa contenda. Na parte de baixo da imagem, um homem ainda vociferante e exaltado, cabelos em pé e olhos muito abertos, tenta intervir na contenda, sob uma nuvem de projéteis que voam. O desenho evoca os ânimos exaltados dos deputados da Assembleia da República, criticando a sua falta de compostura e contenção nas desavenças partidárias. Dentro da lógica do exagero que subjaz à caricatura, o confronto físico entre políticos não pouparia sequer a mobília, o que equivale a rebaixar os representantes do estado ao comportamento de arruaceiros, em botequim de bairro mal-afamado. A caricatura tem por título "Sessão par... 
lamentar" jogando com a palavra "parlamentar", relativa a sessão no parlamento, e a expressão "para lamentar", algo que não se desejaria que tivesse acontecido. Visualmente, é uma imagem carregada de elementos, com fortes sombreados, semelhante ao trabalho de outros caricaturistas de renome na época e, por isso mesmo, representativa de uma estética anterior ao impacto do modernismo. Evidentemente, os conhecedores apontariam diferenças de estilo no trabalho de cada autor de referência, qualidades que não pretendo de forma alguma negar. A generalização fundamentada que faço, relativamente a sombreados, realismo e profusão de elementos na composição, prendese apenas com assinalar aspectos gráficos que marcam diferentes épocas na história da estética do desenho.

No século XX, ao contrário do exemplo apresentado, a caricatura tem tendência a tornar-se uma composição muito mais leve e estilizada. O mestre abordado neste ensaio, Mário de Miranda, será um perfeito exemplo dessa transformação dos padrões do desenho depois do impacto do movimento modernista e da sua influência no sentido do minimalismo, da racionalização da expressão e do respeito pela geometria. Essa viragem no sentido da estilização deve-se ao fato de o desenho moderno estar ligado ao aparecimento de uma nova arquitetura, geométrica e funcional, despojada de ornamento desnecessário, o que libertou o desenho do limite do realismo mimético. Foram os precursores dessa mudança no desenho pintores como Gaugin, Van Gogh, Hodler, Munch e Edward Burne-Jones. ${ }^{2}$ De momento optamos por manter o universo português como nosso horizonte de referência nesta revisão da história da caricatura. Vejamos então um segundo exemplo, uma caricatura dos anos 1980, nesse caso de um outro autor seminal, João Abel Manta:

2. Aliás, foi por influência de Edward Burne-Jones, consagrado pintor pré-raphaelita, que o emblemático Aubrey Vincent Beardsley dedicou-se ao desenho e à caricatura. Cito Beardsley porque é um artista de fama mundial, que se dedicou exclusivamente ao desenho e à caricatura, tendo transformado a estética do desenho no sentido do que viria a ser o desenho moderno. Beardsley esteve ativo na última década do século XIX e tornou-se uma referência na Inglaterra e nos Estados Unidos. 


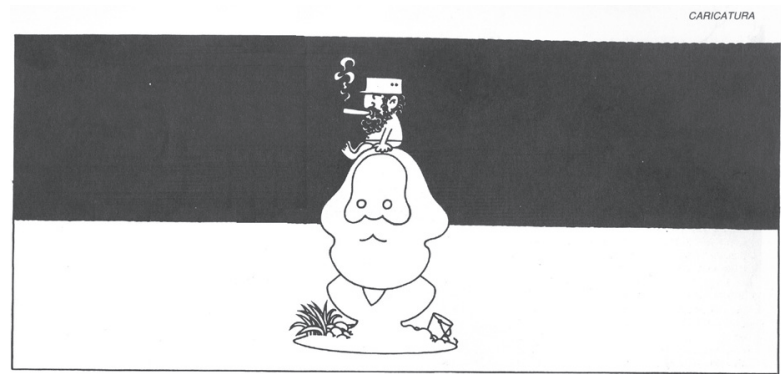

Figura 2 s/d João Abel Manta, apud Osvaldo de Sousa, A caricatura política em Portugal, 1991: 178, 179.

A diferença entre as duas caricaturas é também uma diferença entre dois momentos na história dos padrões estéticos do desenho de caricatura. João Abel Manta representa aqui o traço funcional, a composição despojada, a geometria precisa. O exemplo aqui reproduzido representa Fidel Castro em cima da "sua ilha", após ter transformado Cuba num monumento a Karl Marx, rodeado por mar e céu, num contraste preto/branco que divide a linha do horizonte, onde mais nada figura, a não ser precisamente o isolamento de Cuba em relação ao resto do mundo. Por outro lado, a posição do desenho de Fidel Castro no ponto mais alto da escultura, que representa Cuba, reproduz uma ideia de prepotência autocrática.

Como se notará pelo desenho de João Abel Manta, a caricatura moderna pode funcionar em termos metafóricos, mas outros autores mantêm uma composição mais realista, retratando personagens públicas. Acima, foi referido que em termos de técnica de desenho a caricatura significa exagerar ou deformar certos traços do objeto ou personagem, de forma a provocar o riso. Mas o referido culto do exagero e da deformação grotesca tem um limite, na medida em que o caricaturista também tem de ter o cuidado de manter uma relação de semelhança com o referente real, suficientemente forte para que a personagem, ou episódio, retratada seja reconhecível pelo público.

Em termos de construção de sentido, a caricatura, para além de ser cômica, tem de ser de compreensão rápida e frontal, surpreendendo o seu público com a mesma intensidade com que mantém a capacidade de comunicar. Por outras palavras, uma caricatura banal e previsível não funciona, tal como não é eficaz uma caricatura demasiado hermética. O bom caricaturista tem de ter 
olhar e mão certeira para reconhecer os assuntos "caricaturáveis", isto é, de impato junto do público, para além de conceber a forma de comunicar clara e comicamente um dado conteúdo. Se não atender a todos esses aspectos, não conseguirá prender o público, e reside nesse equilíbrio necessário um dos desafios da arte caricatural. Desde sempre a associação texto/imagem tem uma dimensão pedagógica. Recordemos os vitrais das catedrais da Idade Média que representam episódios da vida dos santos, onde apareciam, como que enroladas na composição da imagem, legendas em latim. A dimensão pedagógica ou moralizante da caricatura mantém-se hoje em dia, como comentário social e político, mas obviamente sem a autoridade institucional da Igreja, caso do exemplo anterior. $\mathrm{Na}$ verdade, o autor da caricatura apresenta uma visão subjetiva de uma dada personagem ou acontecimento e, portanto, apesar de ser um comentário dirigido ao público, representa uma visão pessoal. A pertinência do tema de uma caricatura e a sua capacidade de representar uma opinião mais coletiva determinam o sucesso do caricaturista, tanto mais que a caricatura mantém uma orientação popular e vernácula, se bem que menos indecorosa e agressiva do que no século XIX.

A investigação agora foca um artista que cultivou toda a vida à arte da caricatura, participando no explicitado jogo de ironia e comentário público, segundo os padrões estéticos do desenho moderno. Refiro-me ao artista indiano Mário de Miranda (1926- ), de Goa, cujas caricaturas, assinadas apenas como "Mário", tiveram impacto por toda a Índia e cativaram igualmente a atenção do público internacional. Mário de Miranda foi artista residente em vários países europeus, a convite de companhias, embaixadas ou instituições culturais. ${ }^{3}$ Embora tenha publicado sobretudo no subcontinente indiano, Mário de Miranda é uma referência nos circuitos da caricatura, com obra dispersa por vários jornais. Sua carreira teve início no The Current, do qual passou para The Illustrated Weekly of India, o que lhe permitiu entrar no grupo editorial do Times. A partir daí, para além do Illustrated Weekly, os seus trabalhos apareceram em outros periódicos do grupo, como The Times of Índia (que circulava em nível nacional), The Economic Times e as revistas Femina e Filmfare. Em 1959,

3. Ver o livro Mário de Miranda (MIRANDA, 2008), edição retrospectiva da sua vida e obra realizada por Gerard da Cunha. Muitos dos trabalhos aí reunidos estiveram anteriormente numa exposição comemorativa em honra da obra do autor, na própria Goa, em Panjim, em junho 2008. 
Mário de Miranda recebeu uma bolsa da prestigiada Fundação Calouste Gulbenkian, que lhe permitiu viver em Lisboa por um ano. Posteriormente viveu três anos em Londres, e regressou definitivamente à Índia em 1962, um ano depois da libertação de Goa da ocupação colonial portuguesa. Posteriormente, embora baseado na Índia, Mário de Miranda continuou a viajar e a observar o mundo, comentando-o asua maneira, com traço certo e olhar generoso.

Para se compreender a profundidade e a pertinência das caricaturas que pretendo analisar temos que nos enquadrar no contexto dos estudos pós-coloniais, em articulação com teorias da carnavalização, da sátira e do humor. No que diz respeito à carnavalização e à sátira, tomarei como guia dois estudos de referência: Mikhail Bakhtin, Rabelais and his World (1965), e, de Pater Stallybrass e Aaron White, The Politics and Poetics of Transgression (1986). Quanto ao enquadramento dos estudos pós-coloniais, remeteria para a discussão teórica nos trabalhos de Gayatri Spivak (1987), Homi Bhabha (1990) e Aijaz Ahmad (1992) ou, ainda, toda a discussão teórica definidora de uma área de estudos que encontramos nas antologias críticas de Padimini Mongia (1996), Ian Chambers e Lídia Curti (1996) ou Patrick Williams e Laura Chrisman (1994). Figura tutelar, subjacente ao pensamento político sobre as representações culturais e os discursos dominantes, é Michel Foucault (2002), dificilmente compreendido como o crítico pós-colonial, o que não foi de fato, mas a quem atribuo a mudança de paradigma na forma de ver o poder político da arte e da literatura.

Segundo Bakhtin, o Carnaval era na Idade Média um período "fora da lei", no qual deveriam ser toleradas liberdades usualmente reprimidas. Era um período festivo, com reuniões populares, dança, bebida, comida, e era permitido à população gozar o seu ócio e conviver. Como período "fora do tempo", era permitido aos jograis e saltimbancos criticarem a autoridade de uma forma cômica, brincando com o poder que usualmente os reprimia. Nessas raízes populares, festivas e socialmente excepcionais da carnavalização encontramos a força liberadora e subversiva do cômico, quer seja explorado pelas artes visuais ou pela literatura. Quando François Rabelais escreve Pantagruel (1532) e Gargantua (1534), a sua intenção é satírica, e o autor explora o efeito cômico pelo culto do baixo, deselegante, ou obsceno. Dessa forma está precisamente a celebrar a liberdade popular, vernacular, por oposição ao código de comportamento que era imposto ao povo pelo clero e pela nobreza. Como nos ensina Umberto Eco em $O$ nome da rosa, rir da autoridade é perder-lhe o medo. Ao representar 
elementos da cultura popular, na sua rudeza, na sua falta de contenção, Rabelais celebra o povo e a sua identidade de classe, sem complexos, sem contenção. $\mathrm{O}$ carnaval, na arte, é um "rir de", que é também uma denúncia e uma celebração desinibida dos defeitos comuns dos mortais. Cultivar essa percepção do concreto, confrontando a fealdade a falibilidade humanas, desenvolve o espírito crítico, e esse é por seu turno o princípio de subversão que faz o oprimido resistir à autoridade que o oprime. É na encruzilhada entre a promoção do espírito crítico e a cómica representação dos defeitos humanos que encontramos a caricatura como forma de intervenção social e política, e, por extensão, como relevante objeto de estudo para uma abordagem pós-colonial. Voltemo-nos então para a teoria dos estudos pós-coloniais. O pós-colonial é uma área de crítica literária e de estudos culturais que tem procurado promover o conhecimento das diversas heranças culturais do mundo, corrigindo a pose eurocêntrica que toma a norma da civilização europeia como o modelo da civilização universal. Essa visão colonial e racista relegava todas as outras culturas e sociedades para um plano subalterno, de atraso, de inocência primitiva, de falta de cultura, de decadência. Essas "outras" culturas poderiam, quando muito, tentar "tornarse" europeias, após um longo processo de assimilação da cultura exemplar. No caso dos povos com uma história de colonização a questão era, como tão bem disse Frantz Fanon em Peau noire, masques blancs (1952), recusar esse inculcado complexo de inferioridade, ou seja, recusar a aspiração de ser igual ao colonizador. Enquanto o colonizado quisesse ser "outro", a descolonização seria sempre um processo incompleto. Logo, o desafio da pós-colonialidade, que hoje se coloca a todos os povos, é o de se centrarem na sua própria identidade, na sua forma de contribuir para a herança cultural do mundo, em diálogo com outras culturas. É isso que os intelectuais oriundos das ex-colônias fazem em The Empire Writes Back (2001), uma das antologias de ensaios que procura corrigir a parcialidade da memória cultural ocidental, escrita à imagem da Europa, e silenciando toda a diferença e vitalidade de civilizações alternativas.

Por que se torna pertinente e necessário abordar essas questões para enquadrar a obra gráfica de Mário de Miranda? Porque Mário de Miranda tem um olhar sociológico sensível às barreiras culturais entre os povos que reconhece e demarca, mas ao mesmo tempo vai além dessas barreiras para afirmar as superiores afinidades humanas e afetivas que nos unem. Essa unidade afetiva da humanidade de Mário de Miranda, sempre em paz com a vida, não será, no 
entanto, motivo para deixar esmorecer um olhar crítico sobre contrastes e diferenças, em função de significados simbólicos que são atribuídos à variabilidade cultural. Por outras palavras, não é do estilo de Mário de Miranda ridicularizar nenhuma personagem conhecida, nem reportar-se a acontecimentos políticos. A manifestação do seu olhar crítico, ainda que benevolente, convida-nos a refletir sobre estilos de vida, apreendendo implicações sutis em gestos quotidianos, preconceitos generalizados e padrões de comportamento, aos quais dá uma representação gráfica. Essa matriz criativa implica que o desenho é para Mário de Miranda a forma de apresentar a sua perspectiva, o seu comentário pessoal em relação a determinadas ideologias ou comportamentos dominantes. Tomemos como exemplo a sua representação do turismo. Não é o fenômeno de viajar que Mário de Miranda desconstrói com os seus desenhos, mas antes o ridículo do turismo permeado por ideias coloniais e eurocêntricas. Em primeiro lugar, temos de ter em conta que as atuais rotas turísticas frequentemente reproduzem percursos preferenciais das antigas rotas do colonialismo, alimentando nostalgias imperiais. Por outro lado, o turismo procura o típico, o originalmente local e histórico, salvaguardando para a civilização ocidental as marcas da modernidade e da superioridade tecnológica. Dentro dessa lógica culturalmente racista, a Índia tem sido a vítima de eleição para uma série de estereótipos de fuga espiritual, de licenciosa decadência e de elaborada sensualidade. Mas a questão é mais profunda e virulenta. Na série intitulada "A Índia dos Turistas", Mário de Miranda põe em confronto a Índia de hoje e a imaginação orientalista dos turistas que a visitam, esperando encontrar uma Índia que seja uma vitrine do exótico, parada no tempo, sem vestígios de modernidade (e evidentemente, sem direito a disputar um lugar de destaque na ordem mundial capitalista). $\mathrm{Na}$ série caricatural de Mário de Miranda, a Índia, imaginada pelos turistas vive o seu quotidiano segundo os padrões de uma cultura clássica, ainda usaria elefantes como meio de locomoção, e é um paraíso de vida selvagem (e de caça para o turista ocidental). Por sua vez, os indianos serão surpreendentes personagens, capazes de se sentar em camas de pregos, equilibrar múltiplos potes ou executar misteriosos números de magia e equilibrismo. Não serão nunca na mente dos turistas, a priori, jovens comuns, com acesso à cultura moderna global, a carros último modelo, nem seriam destacados produtores de cinema (Mumbai é a sede da segunda maior indústria cinematográfica do mundo, depois de Hollywood). Em última análise, a Índia moderna é o que o turista não espera ver. Na sua 
mente, só o ocidente é moderno, tecnológico, desenvolvido e a Índia, para se manter autêntica, teria parado no tempo, tendo por obrigação oferecer o exótico, o tradicional e o "nativo" ao olhar do turista.

\section{IH) IXIPía...}
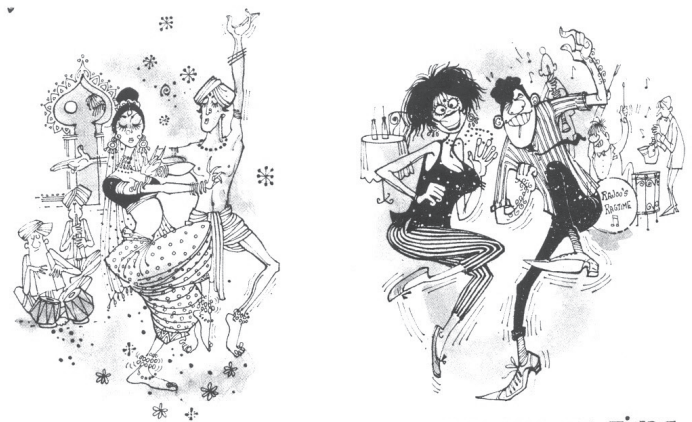

WHAT HE
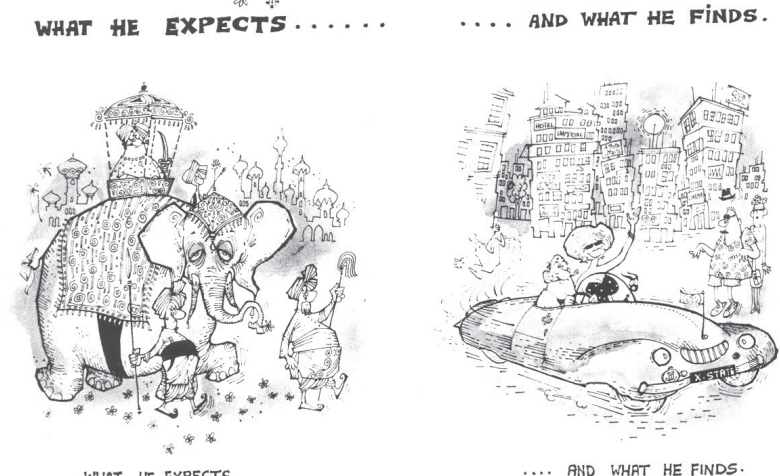

.... AND WHAT HE FINDS.
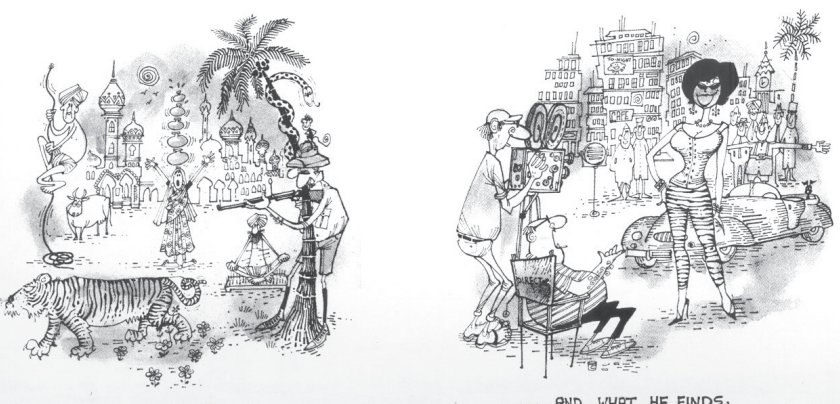

WHAT HE EXPECTS.

. AND WHAT HE FINDS.

Figura 3 Mário de Miranda, "The Tourist's India” in Mário de Miranda, 2008: 103. 
A ironia que subjaz à comparação entre o que o turista encontra na Índia (What he finds) e aquilo que o turista esperava encontrar (What he expects) é um mordaz comentário às projeções estereotipadas do Ocidente sobre o Oriente. Podemos transpor essa reflexão de Miranda para uma lógica pós-colonial em que civilizações previamente marginalizadas por preconceitos coloniais reafirmam a sua identidade numa cultura global. Na caricatura de Mário de Miranda, a diferença entre a representação da Índia moderna e as expectativas do turista denuncia o quanto a visão projectada pelo último está errada. Subjaz a esse riso crítico que convida à cumplicidade uma imensa gentileza, uma afetividade cálida, que reúne povos numa autoconsciência salutar, e corretiva, em lugar de criar novas fronteiras.

\section{A série $A$ Tale of two Cities}

Para complementar a intervenção ideológica que reconheço nos desenhos da série "A Índia dos Turistas" vamos analisar outra série cujo título é a citação de uma obra literária, fundamental no cânone do Ocidente: $A$ Tale of Two Cities (Charles Dickens, 1859). O famosíssimo romance sobre Londres e Paris, que se passa na época da Revolução Francesa, é transformado por Mário de Miranda em duas séries de vinhetas que justapõem Mumbai a Londres (princípio da primeira série reproduzida em anexo) e Mumbai e Paris. O significado dessa reescrita paródica de Um conto de duas cidadest é simbólico. Não só a comparação entre duas cidades europeias passa a formar um triângulo, onde duas cidades centrais na Europa são comparáveis a uma grande cidade indiana, como o estatuto de referente global de Paris e Londres fica comparativamente no mesmo plano de Mumbai. Assim, não só a Índia moderna faz parte do roteiro global do presente, como um artista da Índia, viajado e cosmopolita, pode comentar as cidades europeias, colocando Mumbai num pé de igualdade com Londres e Paris. E há mais: a diferença de Mumbai, barulhenta, excessivamente povoada, caótica, é assumida com todo carinho e orgulho, reforçando positivamente a autoimagem da cultura indiana.

4. Tradução do título do romance de Charles Dickens. 


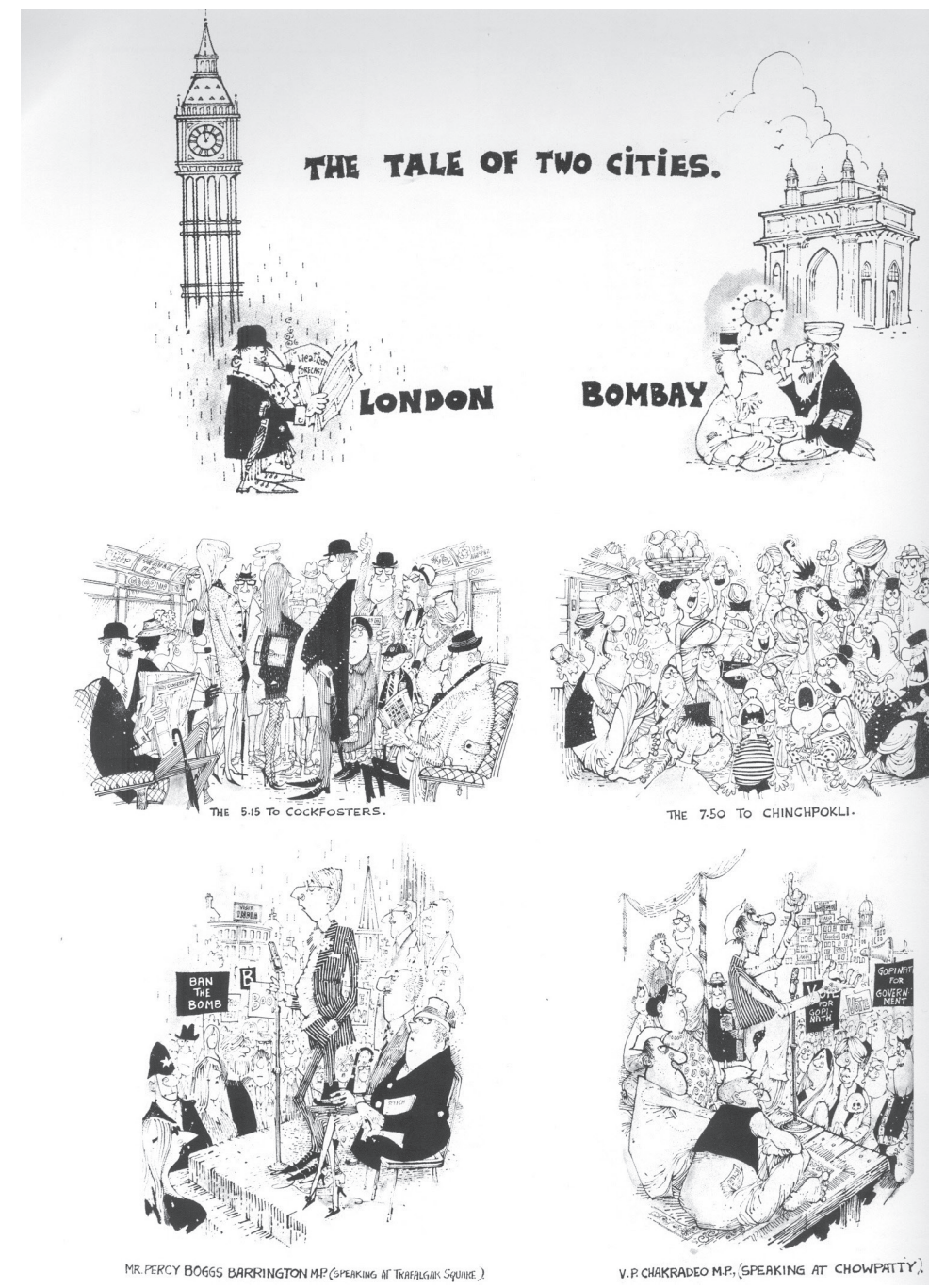

Figura 4 Mário de Miranda "A Tale of Two Cities" in Mário de Miranda, 2008:104.

\section{Culturas híbridas}

Por fim, Mário de Miranda assume com clareza a herança híbrida e póscolonial da Índia a partir do caso de Goa, com o seu catolicismo e a memória 
da colonização portuguesa. As sociedades são o produto das vicissitudes da sua história e não o produto de uma projeção fundamentalista qualquer, marginalizante, ou de afirmação de pureza étnica, como algumas sociedades tão perigosamente insistem em fazer. Como goês que é, Mário de Miranda também revisitou as particularidades de Goa dentro da pluralidade de culturas que convivem no subcontinente indiano, sem esconder a raiz estrangeira de alguns dos seus elementos culturais como é/era o caso da celebração do Carnaval em Goa.

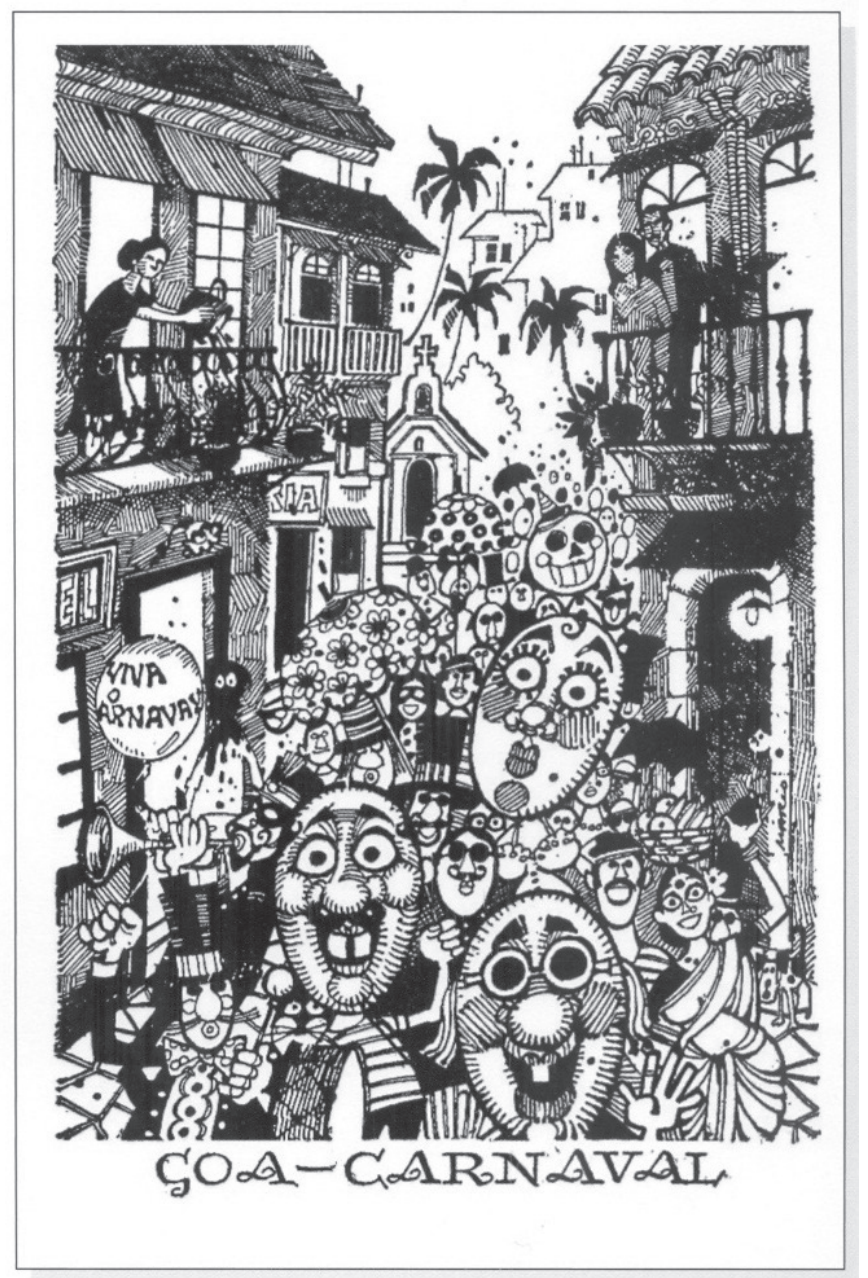

Figura 5 Mário de Miranda, "Goa Postcards", 1964, in Mário de Miranda, 2008: 95. 
Concluimos apontando que Mário de Miranda não ridiculariza o mundo. Comenta-o de uma forma elegante e perspicaz, levando-nos a refletir sobre a realidade na esteira do seu olhar atento. Vital e cativante, Mário de Miranda define-se como um cartunista social, indiretamente político, oferecendo-se a leituras mais profundas, para além do riso ou do sorriso que provoca no seu público.

Nota: Agradeço à Architecture Autonomous, Índia, e a Gerard da Cunha a gentil permissão para publicar as caricaturas de Mário de Miranda incluídas neste artigo.

\section{Referências Bibliográficas}

AHMAD, Aijaz. In Theory: Classes, Nations, Literatures. London/New York: Verso, 1992.

ASCHCROFT, Bill; GRIFFITHS, Gareth; TIFFIN, Helen. The Empire Writes Back: Theory and Practice in Post-colonial Literatures. London/New York: Routledge, 2001.

BAUDELAIRE, Charles. Baudelaire. Oenvres Complètes. Bibliothèque de la Pléiade: Gallimard., s.d.

BAKHTIN, Mikhail. Rabelais and His World (translation by Irene Iswolsky). Bloomington: Indiana University Press, 1984.

BHABHA, Homi. Nation and Narration. London/New York: Routledge, 1990. . The Location of Culture. London/New York: Routledge, 1994.

CHAMBERS, Iain; CURTI, Lídia (Eds.). The Post-Colonial Question, Common Skies, Divided Horizons. London/New York: Routledge, 1996.

DICKENS, Charles. A Tale of two Cities (1859). London: Penguin Books, 1985.

ECO, Umberto. O nome da rosa. Maria Celeste Pinto (Trad.). Lisboa: Difel, 1983.

FEAVER, William. Masters of Caricature. New York: Alfred A. Knopf, 1981.

FOUCAULT, Michel. Microfisica do poder. Roberto Machado (Trad. e Org.). Rio de Janeiro: Edições Graal, 2002.

FANON, Frantz. Peau noire, masques blancs. Paris: Éditions du Séuil, 1952.

SOUSA, Osvaldo de. A caricatura politica em Portugal. Lisboa: Edição Salão Nacional de Caricatura, 1991.

DONALD, Diana; BANERJI, Christiane. Gillray Observed, The Earliest Account of His caricatures in London and Paris. Cambridge: Cambridge University Press, 1999.

MCLEES, Ainslie Armstrong. Baudelaire's "Argot Plastique", Poetic Caricature and Modernism. Athens/London: The University of Georgia Press, 1990. 
PEVSNER, Nikolaus. Os pioneiros do desenho moderno (1936). Lisboa: Editora Ulisseia, 1962.

MONGIA, Padimini (Ed.). Contemporary Postcolonial Theory, a Reader. New York: Arnold, 1996.

MIRANDA, Mário de. Mário de Miranda. Gerard da Cunha (Ed.). Bardez, Goa: Architecture Autonomous and Art Índia, 2008.

RABELAIS, François. Pantagruel (1532). Paris: Classiques de Poche. Gargantua (1534). Paris: Livres de Poche.

SPIVAK, Gayatri. In Other Worlds: Essays in Cultural Politics. New York/London: Methuen, 1987.

STALYBRASS, Peter; WHITE, Allan. The Politics and Poetics of Transgression. New York: Cornell University Press, 1986.

WILLIAMS, Patrick; CHRISMAN, Laura (Eds.). Colonial Discourses and Postcolonial Theory. Hertfordshire: Harvester Wheatsheaf, 1994.

Recebido em 22/02/2011 e aprovado em 08/03/2011. 